\title{
DINAMIKA KEBIJAKAN PENGEMBANGAN BIODIESEL BERBAHAN BAKU KELAPA SAWIT INDONESIA
}

\author{
Dynamics Of Indonesian Palm Oil Biodiesel Policy Development \\ Khoiru Rizqy Rambe*, Nunung Kusnadi, Suharno \\ Balai Pengkajian Teknologi Pertanian (BPTP) Kepulauan Riau \\ *kontak penulis: khoirurambe7@gmail.com
}

\begin{abstract}
Indonesia develops palm oil biodiesel driven by mandatory biodiesel which requires the use of biodiesel as a mixture of fuel oil by 30 percent. However, the development of the biodiesel can cause a trade off CPO for the production of biodiesel and palm cooking oil. The purpose of this study is to analyze the achievement of Indonesia's biodiesel production, and formulate policies for the development of the biodiesel industry with consideration of the balance of the food and non-food sectors. The data used are secondary data obtained from various related agencies such as the Central Bureau of Statistics, Ministry of Agriculture, BAPPEBTI, World Bank and other institutions related to this research which are analyzed by dynamic system models. The results of the analysis show that the development of Indonesian biodiesel has not been able to meet the level of the blending rate according to mandatory biodiesel. Efforts to increase the achievement of the blending rate level can be done by providing biodiesel subsidies. Export duty policy is also needed in an effort to maintain the stability of domestic CPO prices and the price of palm cooking oil. The export duty policy in accordance with Minister of Finance Regulation No. 136 of 2015 is more effectively implemented than Minister of Finance Regulation No. 140 of 2016.
\end{abstract}

Keywords: blending rate; dynamic system; mandatory biodiesel; policy scenario

\begin{abstract}
Abstrak
Indonesia mengembangkan biodiesel berbahan baku kelapa sawit didorong oleh adanya mandatori biodiesel yang mewajibkan pemanfaatan biodiesel sebagai campuran bahan bakar minyak sebesar 30 persen. Namun pengembangan biodiesel tersebut dapat menyebabkan trade off penggunaan CPO untuk produksi biodiesel dan minyak goreng sawit. Tujuan dari penelitian ini yaitu menganalisis ketercapaian produksi biodiesel Indonesia, dan merumuskan kebijakan untuk pengembangan industri biodiesel dengan pertimbangan keseimbangan sektor pangan dan non pangan. Data yang digunakan adalah data sekunder yang diperoleh dari berbagai instansi terkait seperti Badan Pusat Statistik, Kementerian Pertanian, BAPPEBTI, World Bank dan lembaga lainnya yang terkait dengan penelitian ini yang dianalisis dengan model sistem dinamik. Hasil analisis menunjukkan bahwa Pengembangan biodiesel Indonesia belum mampu memenuhi tingkat blending rate sesuai mandatori biodiesel. Upaya peningkatan ketercapaian tingkat blending rate dapat dilakukan dengan pemberian subsidi biodiesel. Kebijakan bea keluar juga dibutuhkan dalam upaya menjaga stabilitas harga CPO domestik dan harga minyak goreng sawit. Kebijakan bea keluar sesuai Peraturan Menteri Keuangan No. 136 Tahun 2015 lebih efektif diterapkan dibandingkan Peraturan Menteri Keuangan No. 140 Tahun 2016.
\end{abstract}

Kata kunci : blending rate, mandatori biodiesel, sistem dinamik, skenario kebijakan 
Sitasi: Khoiru Rizqy Rambe, Nunung Kusnadi, Suharno, 2019. Dinamika Kebijakan Pengembangan Biodiesel Berbahan Baku Kelapa Sawit Indonesia, JSEP 15 (3): 239 252.

\section{Pendahuluan}

Pengembangan biodiesel di Indonesia didorong oleh Kebijakan Mandatori Biodiesel melalui Permen ESDM No. 32 Tahun 2008 tentang penyediaan, pemanfaatan, dan tata niaga bahan bakar nabati sebagai bahan bakar lain. Industri biodiesel sebagai sumber energi terbarukan semakin berkembang disebabkan oleh semakin meningkatnya kebutuhan Indonesia terhadap sumber energi sementara sumber energi dari minyak bumi ketersediaannya semakin menipis.

Indonesia mengembangkan industri biodiesel berbahan baku minyak kelapa sawit karena komoditas kelapa sawit memiliki potensi terbesar untuk diolah menjadi biodiesel di Indonesia. Potensi tanaman kelapa sawit cukup tinggi dengan produktivitas 3.6 - 4 ton/ha dan didukung oleh luas lahan yang jauh dibandingkan tanaman lainnya sehingga memiliki potensi sebesar 31914476 kiloliter biodiesel (EBTKE 2013).

Minyak kelapa sawit yang digunakan untuk kepentingan pengembangan biodiesel juga dimanfaatkan oleh berbagai industri hilir kelapa sawit di Indonesia yang salah satunya adalah industri minyak goreng sawit. Minyak goreng sawit sebagai salah satu kebutuhan pokok masyarakat Indonesia menyerap rata-rata pangsa pasar sebesar 86.64 persen pada tahun 2002 sampai 2008 dibanding minyak goreng jenis lainnya (Sipayung \& Purba 2015). Kebutuhan terhadap minyak goreng sawit akan semakin meningkat dengan meningkatnya jumlah penduduk Indonesia sebesar 1.38 persen per tahun pada selang tahun 2010 hingga 2015 (BPS 2016). Hal tersebut menyebabkan minyak goreng sawit dapat dikategorikan sebagai komoditas yang strategis, karena kelangkaan minyak goreng sawit dapat menimbulkan dampak ekonomis yang cukup berarti bagi perekonomian nasional. Oleh sebab itu, dibutuhkan analisis yang komprehensif dalam mengantisipasi pengembangan biodiesel berbahan baku minyak kelapa sawit di Indonesia agar kepentingan industri produk turunannya yang lain terutama bahan pangan tidak terganggu.

Pemerintah melakukan perubahan ketiga atas kebijakan mandatori biodiesel melalui Permen ESDM No. 12 Tahun 2015 dengan meningkatkan kewajiban minimal pemanfaatan biodiesel sebagai campuran bahan bakar minyak menjadi 30 persen. Keseriusan pemerintah dalam pengembangan industri biodiesel semakin ditunjukkan dengan dikeluarkannya Peraturan Menteri ESDM No. 26 Tahun 2015, yaitu badan usaha bahan bakar nabati jenis biodiesel berhak memperoleh pembiayaan biodiesel dari Badan Pengelola Dana Perkebunan Kelapa Sawit. Dana tersebut merupakan pungutan atas ekspor komoditas perkebunan kelapa sawit dan turunannya serta iuran dari pelaku usaha perkebunan kelapa sawit sesuai dengan Peraturan Presiden No. 61 Tahun 2015. Dengan berbagai kebijakan yang telah dikeluarkan tersebut, pemerintah menetapkan target produksi biodiesel pada tahun 2025 sebesar 22.41 juta kiloliter.

Berdasarkan perhitungan realisasi produksi biodiesel sesuai kebijakan mandatori biodiesel Indonesia hingga tahun 2013 masih jauh dari target yang ditetapkan pemerintah dengan tingkat blending rate 4.40 persen, sementara target 
yang ditetapkan 10 persen (Sipayung \& Purba 2015). Realisasi yang jauh dari target tersebut terkendala beberapa hal yang menjadi penghambat pengembangan biodiesel diantaranya biaya produksi yang tinggi dan tidak tersedianya pasar biodiesel karena hanya Pertamina yang bertindak sebagai konsumen utama. Untuk mengatasi hal tersebut, perlu dilakukan analisis untuk mengetahui tingkat ketercapaian produksi biodiesel berbahan baku minyak kelapa Indonesia dan alternatif kebijakan untuk pengembangan biodiesel tersebut.

Tujuan penelitian ini adalah untuk menganalisis ketercapaian produksi biodiesel sehingga diketahui kemampuan industri biodiesel Indonesia dalam memenuhi target mandatori biodiesel. Selain itu, penelitian ini juga bertujuan untuk mencoba menganalisis kebijakan untuk pengembangan biodiesel dengan pertimbangan keseimbangan sektor pangan dan non pangan. Penelitian ini mengkaji dinamika pengembangan biodiesel yang difokuskan pada ketersediaan minyak kelapa sawit untuk kepentingan pengembangan industri hilir domestik dan ekspor. Industri hilir kelapa sawit yang dianalisis hanya industri biodiesel dan industri minyak goreng sawit. Industri minyak goreng sawit dianalisis berdasarkan dinamika kebutuhan pangan yang terkait dengan populasi penduduk dan harga minyak goreng sawit. Industri biodiesel dianalisis berdasarkan dinamika pertumbuhan produksi biodiesel dan target produksi biodiesel yang ditetapkan pemerintah. Aspek kebijakan yang dianalisis dilakukan terhadap perspektif ketersediaan bahan baku minyak goreng sawit untuk pangan dan biodiesel yang optimal sehingga dapat menjamin terpenuhinya pasokan pangan dan energi.

\section{Metode Penelitian}

Penelitian ini menggunakan analisis sistem dinamik sehingga dalam perancangan model dimulai dengan konspetualisasi sistem. Konseptualisasi sistem dilakukan dengan menentukan faktor-faktor penting yang berpengaruh dalam sistem yang digambarkan dalam bentuk diagram umpan balik atau causal loop diagram yang saling berhubungan. Gambar 1 adalah diagram lingkaran kausal menunjukkan struktur utama dari model dan hubungan antara tiga sektor yaitu sektor industri biodiesel, sektor industri minyak goreng, dan sektor ekspor CPO. Panah antara variabel mengindikasikan penyebab dan akibatnya serta perubahan dalam satu variabel mempengaruhi variabel berikutnya. 


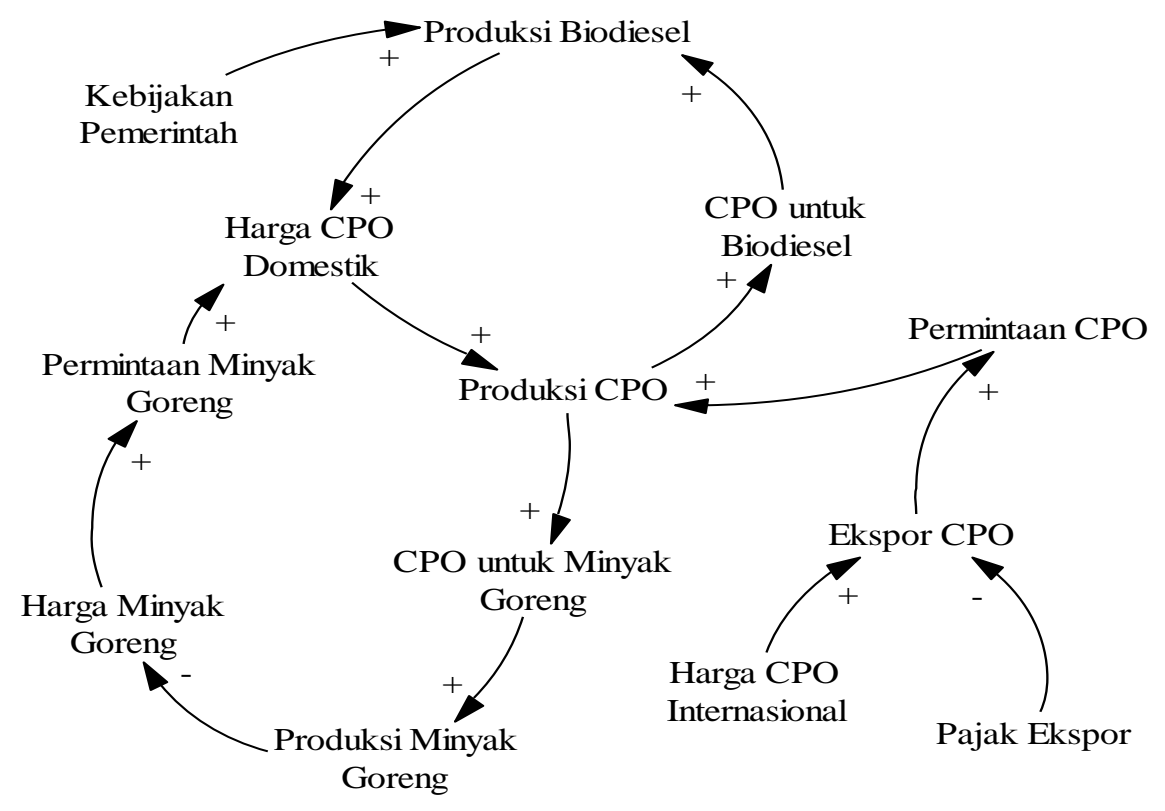

Gambar 1 Diagram lingkaran kausal

Kemudian berdasarkan causal loop diagram (CLD) dibangun sebuah model stock and flow. Model stock and flow yang dibangun dalam penelitian ini terdiri dari empat subsistem model yang antara lain subsistem hulu kelapa sawit, subsistem minyak goreng sawit, subsistem biodiesel, dan subsistem ekspor (Lampiran 1). Keempat subsistem ini akan dianalisis pengaruhnya terhadap kesimbangan pasar $\mathrm{CPO}$ domestik dengan beberapa asumsi yang digunakan antara lain :

1. Permintaan CPO domestik hanya dihitung berdasarkan permintaan CPO untuk minyak goreng sawit, biodiesel dan kebutuhan ekspor CPO. Permintaan CPO untuk minyak goreng sawit dihitung berdasarkan konsumsi perkapita minyak goreng sawit sebesar $8.1 \mathrm{~kg} /$ kapita pada tahun 2013.

2. Supply CPO hanya dihitung berdasarkan jumlah produksi CPO dalam negeri dengan produktivitas 2.66 ton per hektar lahan sawit, dan impor CPO diabaikan.

3. Populasi penduduk Indonesia berdasarkan data Statistik Indonesia 2016 dengan jumlah penduduk sebesar 248.818 juta jiwa dengan laju pertumbuhan penduduk sebesar 1.38 persen.

4. Supply CPO dunia dalam model penelitian ini hanya dihitung berdasarkan produksi CPO Indonesia dan Malaysia dengan laju pertumbuhan produksi sebesar 4 persen per tahun. Sementara demand CPO dunia direpresentasikan dari ekspor CPO Indonesia dan Malaysia dengan laju pertumbuhan ekspor sebesar 7.6 persen.

5. Penetapan bea keluar dalam model disesuaikan dengan Peraturan Menteri Keuangan No. 140 Tahun 2016 yang mengganti sistem tarif bea keluar secara persentase menjadi nilai yang konstan.

6. Kebutuhan solar Indonesia berdasarkan data Pertamina sebesar 30.10 juta kiloliter pada tahun 2013 dengan laju pertumbuhan konsumsi solar sebesar 4 persen.

7. Periode analisis model dinamik pada penelitian ini sebanyak 12 tahun dari periode tahun 2017 sampai dengan 2028. 
Data yang digunakan dalam penelitian ini merupakan data sekunder. Data diperoleh dari berbagai sumber instansi yang terkait dengan penelitian yang antara lain (BAPPEBTI), Kementerian Pertanian, Badan Ketahanan Pangan, Badan Pusat Statistik, Pertamina, World Bank, dan Department of Statistical Malaysia (DOSM). Data yang dianalisis pada penelitian ini adalah data pada tahun 2015 dari variabel variabel yang terdapat pada model sistem dinamik.

\section{Validasi Model}

Sebuah model sistem dinamik membutuhkan proses validasi agar model yang dibangun secara sistematis tersebut dapat diakui keakuratannya dalam menjelaskan tujuan akhir pembentukan model. Sesuai dengan Barlas (1996), proses validasi model sistem dinamik yang dilakukan dalam penelitian ini mengikuti beberapa urutan logis sebagai berikut:

1. Penyesuaian struktur model dengan teori ekonomi

2. Penyesuaian struktur model dengan studi empiris yang terkait penelitian

3. Pengujian hasil analisa model dengan keadaan aktual

4. Pengujian tingkat kesesuaian hasil analisa model dengan data riil

Pengukuran kesesuaian model dalam merepresentasikan dunia nyata secara statistik digunakan Mean Absolute Percentage Error (MAPE) yang dihitung dengan rumus (Makridakis et al. 1995) :

$$
\mathrm{MAPE}=\frac{1}{n} \sum_{i=1}^{n} \frac{|X t-Y t|}{X t} \times 100 \%
$$

Dimana : Xt adalah data aktual secara statistik, Yt adalah data hasil simulasi model, dan $n$ adalah jumlah data. Model sistem dinamik yang dibangun dianggap valid apabila nilai MAPE lebih kecil dari 5 persen. Hasil simulasi terhadap luas lahan aktual kelapa sawit Indonesia pada periode tersebut menunjukkan tingkat kesesuaian yang cukup baik. Nilai MAPE pada uji validasi model terhadap luas lahan yaitu sebesar 4.63 persen yang berarti tingkat kesalahan rata - rata model dalam merepresentasikan luas lahan kelapa sawit hanya 4.63 persen. Sementara nilai MAPE pada uji validasi yang dilakukan terhadap produksi kelapa sawit Indonesia tahun 2009 hingga 2013 yaitu sebesar 1.32 persen.

\section{Skenario Simulasi}

Penelitian ini akan melakukan simulasi sebagai berikut :

1. Skenario kondisi awal, untuk menganalisis dampak pengembangan biodiesel sesuai target mandatori biodiesel yang dicanangkan pemerintah dan menganalisis jumlah kebutuhan biodiesel Indonesia pada tahun 2025.

2. Skenario pemberian subsidi biodiesel untuk menganalisis dampak subsidi terhadap permintaan biodiesel Indonesia dan jumlah subsidi yang diberikan pada produsen biodiesel Indonesia.

3. Skenario kebijakan bea keluar mengikuti Peraturan Menteri Keuangan No. 136 Tahun 2015. 


\section{Hasil dan Pembahasan}

\section{Ketercapaian Mandatori Biodiesel Indonesia}

\section{a. Tanpa Subsidi}

Biodiesel merupakan sumber energi terbarukan yang dianggap mampu menggantikan penggunaan energi dari bahan bakar fosil. Menurut Hidayatno et al. 2010, pengembangan biodiesel memberikan banyak keuntungan bagi Indonesia secara ekonomis meskipun disisi lain berdampak pada lingkungan seperti deforestasi dan hilangnya biodiversitas.

Pemerintah Indonesia melalui roadmap pengembangan biodiesel ketahanan energi Indonesia 2014 menetapkan target produksi biodiesel sebesar 22.41 juta kL pada tahun 2025. Namun berdasarkan analisis dengan mengikuti Permen ESDM No. 12 Tahun 2015 yaitu campuran biodiesel sebesar 30 persen. Peraturan tersebut menetapkan langkah - langkah peningkatan campuran biodiesel dalam bahan bakar minyak mulai dari 20 persen pada tahun 2017 - 2019. Pemanfaatan biodiesel sebesar 30 persen baru berlaku sejak Januari 2020 sehingga kebutuhan biodiesel Indonesia pada tahun 2025 hanya sebesar 15.15 juta kL (Gambar 2). Dengan demikian angka yang ditetapkan pemerintah jauh lebih tinggi dari kebutuhan biodiesel Indonesia sesuai mandatori biodiesel yang telah ditetapkan.

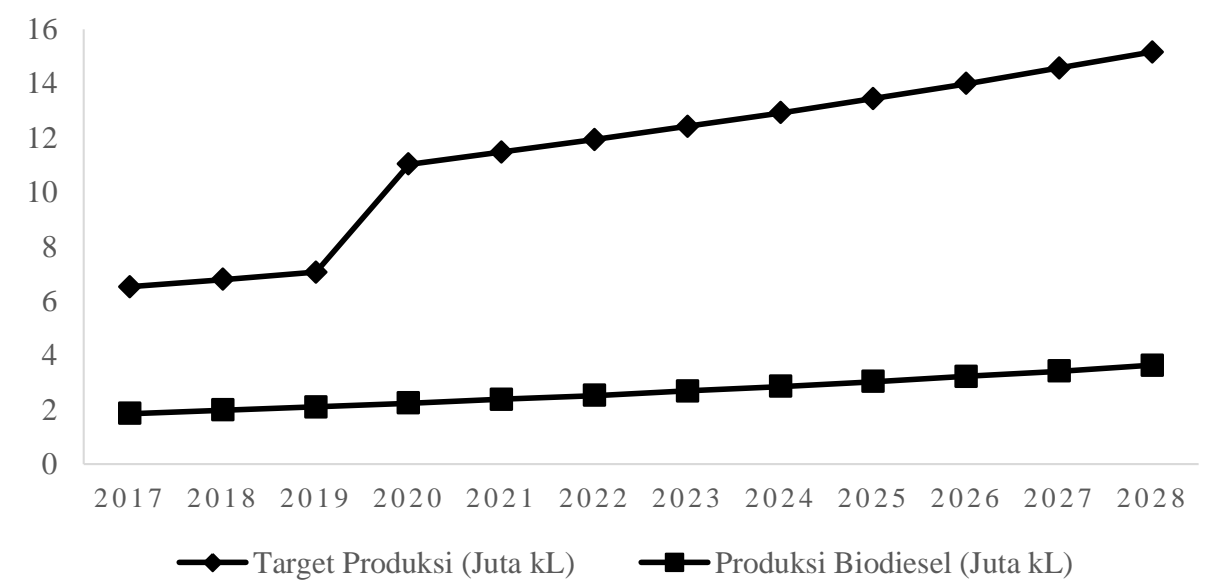

Gambar 2 Ketercapaian target produksi biodiesel Indonesia tanpa subsidi

Berdasarkan prediksi yang dilakukan, target produksi biodiesel yang merupakan jumlah kebutuhan biodiesel untuk memenuhi target mandatori biodiesel jauh lebih tinggi dari tingkat produksi biodiesel Indonesia. Hingga tahun 2019, selisih produksi biodiesel tidak terlalu signifikan karena target blanding rate yang ditetapkan pemerintah hanya 20 persen, kemudian sejak Januari 2020 diberlakukan tingkat blending rate sebesar 30 persen. Dengan peningkatan tingkat blending rate yang hendak dicapai tentu saja menyebabkan kenaikan kebutuhan biodiesel Indonesia. Namun dengan laju produksi biodiesel yang ada, tingkat kebutuhan biodiesel tersebut tidak dapat tercapai hingga akhir masa periode analisis yaitu tahun 2028. Dengan tingkat produksi biodiesel tersebut, ketercapaian blending rate pada tahun 2025 hanya mencapai 4.51 persen (Gambar 3). Hal yang sama juga dinyatakan Handoko et al. 2012, bahwa ketercapaian kontribusi biodiesel dalam bauran energi Indonesia 2025 sulit 
untuk dicapai dengan struktur dan kondisi saat ini terutama tanpa perbaikan kepastian pasar dan komitmen jangka panjang pemerintah.

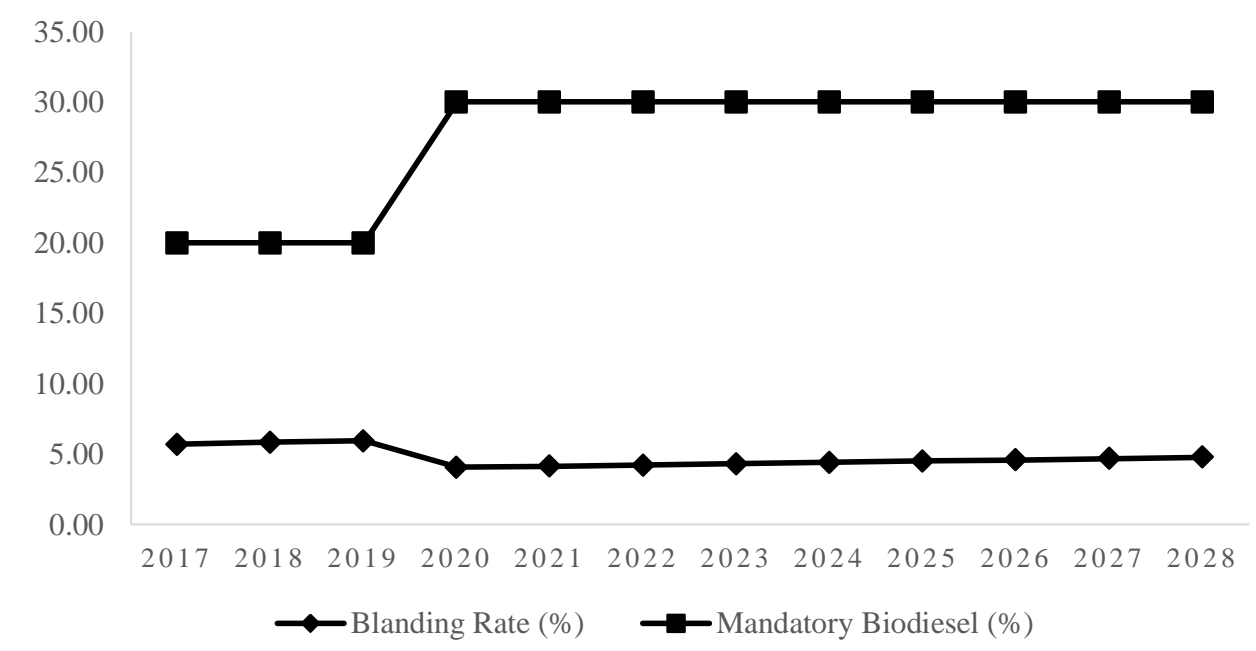

Gambar 3 Ketercapaian tingkat blending rate mandatori biodiesel Indonesia tanpa subsidi.

\section{b. Pemberian Subsidi}

Salah satu cara pemerintah mengatasi permasalahan tingginya biaya produksi biodisesl yaitu dengan memberikan subsidi bagi produsen biodiesel sebagai insentif untuk berproduksi. Subsidi ini diberikan sesuai dengan Peraturan Menteri ESDM No. 26 Tahun 2015, yaitu badan usaha bahan bakar nabati jenis biodiesel berhak memperoleh pembiayaan biodiesel dari Badan Pengelola Dana Perkebunan Kelapa Sawit.

Pemberian subsidi biodiesel ini sejalan dengan Handoko et al. 2012 yang menyebutkan bahwa target kontribusi biodiesel dalam bauran energi Indonesia 2025 dapat dicapai dengan intervensi kebijakan-kebijakan yang antara lain : (i) Pencabutan subsidi solar ke level harga pasar, (ii) Perluasan implementasi kewajiban penggunaan campuran biodiesel ke solar di sektor transportasi non PSO, industri dan pembangkit listrik sehingga mencapai target minimum campuran sebesar 10 persen untuk memberikan kepastian pasar, (iii) Pengenaan pajak lingkungan terhadap solar sebesar minimum 5 persen sebagai tambahan atas pengenaan Pajak Pertambahan Nilai (PPN) dan Pajak Bahan Bakar Kendaraan (PBBKB), dan (iv) Subsidi biodiesel minimum sebesar Rp2 000/liter. Wijaya (2015), juga menyebutkan bahwa dibutuhkan kebijakan tambahan untuk mendukung pelaksanaan kebijakan mandatori biodiesel yaitu pemberian insentif bahan baku biodiesel (CPO), pemberian subsidi kepada produsen biodiesel hingga minimal memenuhi kelayakan ekonomi untuk berproduksi.

Berdasarkan analisis yang dilakukan, pemberian subsidi ini terbukti efektif dalam meningkatkan ketercapaian mandatori biodiesel Indonesia meskipun belum mencapai target produksi sesuai mandatori biodiesel (Gambar 4). 


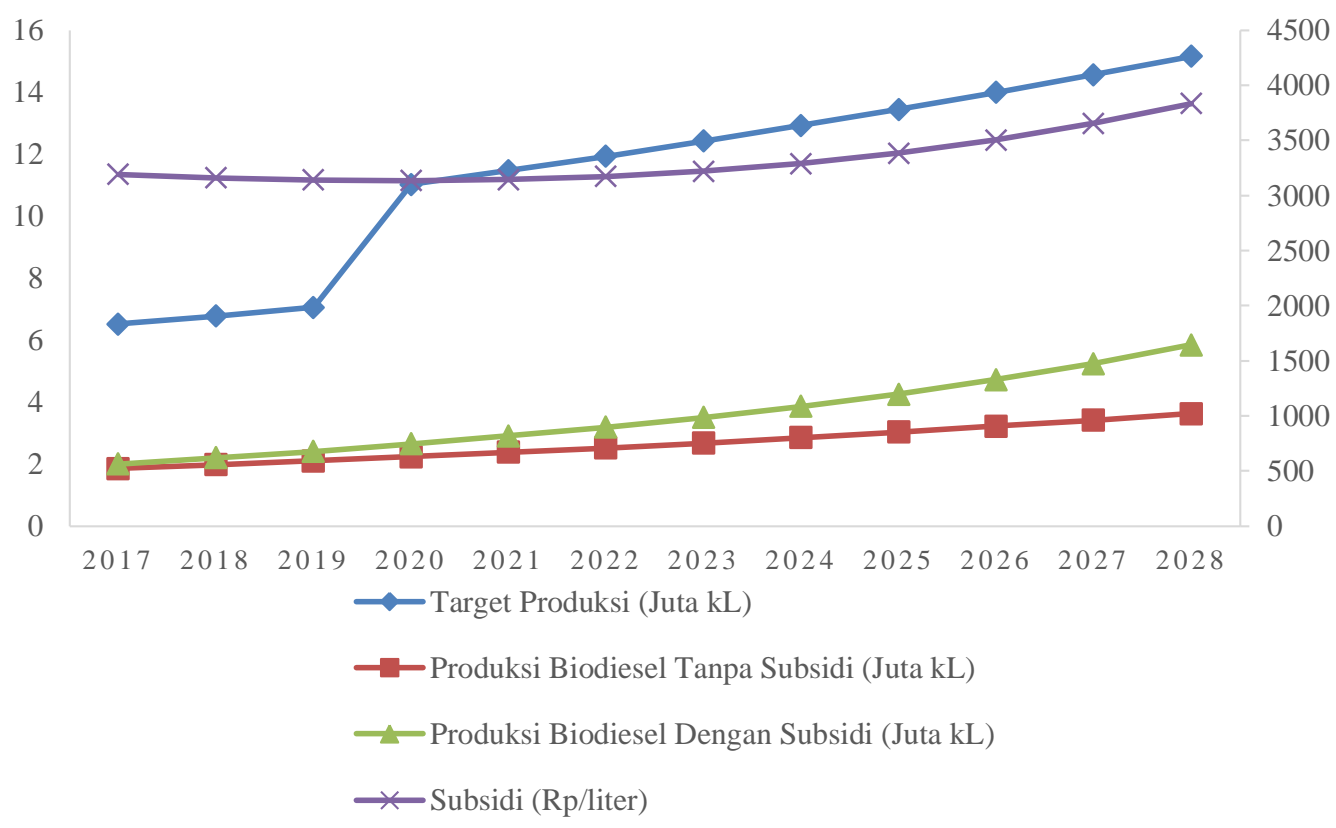

Gambar 4 Perbandingan produksi biodiesel Indonesia dengan adanya subsidi

Dengan adanya subsidi harga, permintaan biodiesel meningkat sehingga terdapat keterjaminan pasar bagi produsen sehingga menjadi insentif untuk memproduksi biodiesel. Produksi biodiesel dengan adanya kebijakan subsidi mengalami peningkatan rata -rata 30.7 persen hingga tahun 2028. Besaran subsidi yang diberikan pemerintah juga berfluktuatif dengan kecenderungan yang semakin meningkat (Gambar 4). Besaran rata - rata subsidi biodiesel tiap tahunnya berkisar antara Rp3 133/liter hingga Rp3 834/liter.

Besaran subsidi rata - rata tiap tahun yang dihasilkan dalam penelitian ini tidak jauh berbeda dari usulan besaran subsidi biodiesel dihasilkan tahun 2013 sebesar yaitu Rp 2 845. Nilai besaran subsidi pada tahun 2013 tersebut dipengaruhi oleh fluktuasi harga bahan baku. nilai tukar rupiah terhadap dollar dan harga minyak mentah (crude oil) sehingga penentuan besaran subsidi berikutnya harus mempertimbangkan variabel-variabel tersebut. Penentuan besaran subsidi oleh pemerintah berdasarkan selisih antara HIP (harga MOPS bulan sebelumnya) dengan MOPS bulan berjalan tidak relevan karena harga jual biodiesel selalu berada di atas harga MOPS yang dibentuk oleh harga minyak mentah (crude oil). Berdasarkan hal tersebut. maka perhitungan besaran subsidi sebaiknya adalah harga jual (produsen) dikurangi HIP (pemerintah) agar dapat menutupi keseimbangan harga jual biodiesel (Sembiring 2015).

\section{Simulasi Skenario Kebijakan Bea Keluar}

Saat ini, industri hilir sawit yang telah berkembang dengan baik dan stabil di Indonesia adalah industri minyak goreng sawit yang telah menjadi salah satu kebutuhan pokok masyarakat Indonesia. Dengan adanya mandatori biodiesel diharapkan mampu meningkatkan pemanfaatan $\mathrm{CPO}$ di dalam negeri sehingga keterjaminan ketersediaan CPO harus dijaga. Oleh sebab itu pemerintah melakukan kebijakan bea keluar terhadap ekspor CPO Indonesia. 
Peraturan bea keluar yang dianalisis pada penelitian ini adalah dua peraturan terakhir yang diberlakukan di Indonesia yaitu Peraturan Menteri Keuangan No. 136 Tahun 2015 dan Peraturan Menteri Keuangan No. 140 Tahun 2016. Peraturan Menteri Keuangan No. 136 tahun 2015 merupakan perubahan dari Peraturan Menteri Keuangan No. 72 Tahun 2012 dimana nilai bea keluar dihitung berdasarkan persentase pada beberapa kelompok harga referensi yang ditetapkan pemerintah. Peraturan ini kemudian diperbaharui lagi dengan dikeluarkannya peraturan Menteri Keuangan No. 140 Tahun 2016 yang mengganti sistem tarif berupa persentase menjadi nilai yang konstan. Kedua periode kebijakan bea keluar ini dilakukan simulasinya dengan model sistem dinamik untuk mengetahui dampaknya terhadap harga CPO domestik sebagai bahan baku biodiesel dan harga minyak goreng sawit yang telah menjadi kebutuhan pokok di Indonesia.

\section{a. Harga CPO Domestik}

Pengembangan biodiesel sebagai upaya hilirisasi kelapa sawit memberikan dampak yang kecil terhadap perubahan harga CPO domestik dikarenakan proporsi produksi biodiesel masih kecil dibandingkan produk turunan kelapa sawit lain. Berdasarkan hasil prediksi awal harga CPO domestik pada skenario Peraturan Menteri Keuangan No.140 Tahun 2016 pada tahun 2017 sebesar Rp8 286 / kg kemudian terjadi penurunan harga hingga tahun 2020 dimana harga sebesar Rp8 221 lalu meningkat menjadi Rp9 027 pada tahun 2028. Atau dapat dikatakan bahwa dampak pengembangan biodiesel menyebabkan laju kenaikan harga CPO domestik rata - rata 0.77 persen pertahun pada periode tersebut (Tabel 1).

Tabel 1 Hasil simulasi skenario terhadap harga CPO domestik

\begin{tabular}{cccc}
\hline Tahun & $\begin{array}{c}\text { Harga CPO } \\
\text { Domestik } \\
\text { Tanpa BK } \\
(\mathrm{Rp} / \mathrm{Kg})\end{array}$ & $\begin{array}{c}\text { Harga CPO Domestik } \\
\text { Skenario Permenkeu } \\
\text { No.136 Tahun } 2015 \\
(\mathrm{Rp} / \mathrm{Kg})\end{array}$ & $\begin{array}{c}\text { Harga CPO Domestik } \\
\text { Skenario Permenkeu } \\
\text { No.140 Tahun 2016 } \\
(\mathrm{Rp} / \mathrm{Kg})\end{array}$ \\
\hline 2017 & 8288 & 8275 & 8286 \\
2018 & 8252 & 8232 & 8250 \\
2019 & 8231 & 8202 & 8227 \\
2020 & 8226 & 8188 & 8221 \\
2021 & 8239 & 8192 & 8233 \\
2022 & 8273 & 8215 & 8265 \\
2023 & 8329 & 8261 & 8320 \\
2024 & 8410 & 8330 & 8400 \\
2025 & 8520 & 8426 & 8508 \\
2026 & 8660 & 8552 & 8646 \\
2027 & 8833 & 8711 & 8818 \\
2028 & 9044 & 8905 & 9027 \\
\hline
\end{tabular}

Perkiraan dampak pengembangan ini dengan menggunakan asumsi bahwa kebijakan subsidi diberlakukan untuk mengatasi permasalahan tingginya harga biodiesel sehingga terjadi kenaikan permintaan biodiesel. Namun meskipun demikian, target mandatori juga belum tercapai dan dampak yang sama terjadi di Malaysia, dimana pengembangan biodiesel tidak berpengaruh banyak pada 
perubahan harga CPO karena porsi permintaan CPO untuk produksi biodiesel masih kecil (Mohammadi et al. 2015).

Peraturan Menteri Keuangan No. 140 Tahun 2016 tersebut mengatur besaran bea keluar dengan nilai konstan pada beberapa kategori harga referensi dari harga referensi di bawah USD750 hingga di atas USD1250 dengan selang tiap kategori yaitu USD50. Besaran bea keluar yang digunakan dalam penelitian ini mengikuti prediksi harga CPO internasional dalam model yang berada diantara USD700 hingga USD850 sehingga kategori kebijakan yang diberlakukan yaitu saat harga referensi dibawah USD750 tidak dikenakan bea keluar, harga referensi diantara USD750 hingga USD800 dikenakan bea keluar USD 3/ton, dan saat harga referensi diantara USD800 hingga USD850 dikenakan bea keluar sebesar USD 18/ton.

Skenario selanjutnya yang dianalisis adalah Peraturan Menteri Keuangan No. 136 Tahun 2015. Berdasarkan peraturan ini ekspor CPO dikenakan bea keluar dengan persentase tertentu pada selang harga referensi yang sama dengan Peraturan Menteri Keuangan No. 140 Tahun 2016. Besaran bea keluar yang digunakan dalam analisis ini antara lain harga referensi dibawah USD750 tidak dikenakan bea keluar, harga referensi diantara USD750 hingga USD800 dikenakan bea keluar 3 persen, dan saat harga referensi diantara USD800 hingga USD850 dikenakan bea keluar sebesar 18 persen. Hasil analisis menunjukkan bahwa skenario Peraturan Menteri Keuangan No.136 Tahun 2015 memprediksi harga CPO domestik yang lebih rendah dibandingkan Peraturan Menteri Keuangan No. 140 Tahun 2016. Prediksi harga CPO domestik pada skenario Peraturan Menteri Keuangan No.136 Tahun 2015 pada tahun 2017 sebesar Rp8 275/kg dan meningkat menjadi Rp8 905/kg (Tabel 1). Prediksi harga tersebut secara rata-rata lebih kecil 0.64 persen dibandingkan skenario Peraturan Menteri Keuangan No.140 Tahun 2016.

Secara teoritis penerapan kebijakan bea keluar menyebabkan semakin tingginya biaya bagi produsen CPO yang akan melakukan ekspor CPO ke luar negeri. Peningkatan biaya tersebut akan menjadi batasan bagi produsen untuk melakukan ekspor sehingga diharapkan produsen $\mathrm{CPO}$ Indonesia menjual produknya lebih banyak di dalam negeri. Dengan demikian harga CPO domestik akan turun karena penawarannya meningkat di dalam negeri. Hal ini terbukti saat dilakukan analisis harga CPO domestik tanpa memberlakukan kebijakan bea keluar yaitu harga pada tahun 2017 sebesar Rp8 288/kg dan harga pada tahun 2028 mencapai Rp9 044/kg (Tabel 1). Harga CPO domestik yang terbentuk tanpa adanya kebijakan bea keluar lebih besar dibandingkan kedua skenario penetapan bea keluar yang dianalisis. Meskipun Rifin (2014) menyatakan bahwa kebijakan pajak ekspor tidak mempengaruhi harga CPO domestik selama masa implementasinya di Indonesia. Menurut Obado et al. 2009, tingkat pajak yang direkomendasikan adalah sebesar 11.3 persen agar efektif dalam menjaga industri kelapa sawit dalam negeri.

\section{b. Harga Minyak Goreng Sawit}

Harga minyak goreng sawit penting untuk dijaga tetap stabil agar tidak mengganggu ekonomi rumah tangga masyarakat Indonesia. Berdasarkan hasil prediksi awal dapat diketahui bahwa harga minyak goreng sawit akan semakin 
meningkat sebagai dampak adanya pengembangan biodiesel berbahan baku minyak kelapa sawit. Harga minyak goreng sawit pada tahun 2017 sebesar Rp13 473/ kg dan meningkat dengan rata - rata 2.6 persen pertahun hingga tahun 2028 menjadi sebesar Rp18 068/ kg (Tabel 2). Prediksi ini merupakan hasil skenario kebijakan bea keluar terkini yaitu Peraturan Menteri Keuangan No.140 Tahun 2016.

Kenaikan harga CPO domestik akibat pengembangan biodiesel akan berpengaruh pada harga produk - porduk turunannya seperti minyak goreng sawit ini menyebabkan perlunya kebijakan untuk menjaga harga CPO domestik tetap stabil. Skenario Peraturan Menteri Keuangan No.136 Tahun 2015 menunjukkan hasil penurunan harga minyak goreng sawit meskipun dengan selisih yang sangat kecil dibandingkan pada prediksi awal yaitu skenario Peraturan Menteri Keuangan No.140 Tahun 2016. Rata - rata penurunan harga minyak goreng sawit dengan penetapan bea keluar Peraturan Menteri Keuangan No.136 Tahun 2015 hanya 0.04 persen pertahun pada periode 2017 hingga 2028.

Tabel 2 Hasil skenario simulasi terhadap harga minyak goreng sawit

\begin{tabular}{lccc}
\hline Tahun & $\begin{array}{c}\text { Harga Minyak } \\
\text { Goreng Sawit } \\
\text { Tanpa BK (Rp/Kg) }\end{array}$ & $\begin{array}{c}\text { Harga Minyak } \\
\text { Goreng Sawit } \\
\text { Skenario Permenkeu } \\
\text { No.136 Tahun 2015 } \\
(\mathrm{Rp} / \mathrm{Kg})\end{array}$ & $\begin{array}{c}\text { Harga Minyak Goreng } \\
\text { Sawit Skenario } \\
\text { Permenkeu No.140 Tahun } \\
\text { 2016 (Rp/Kg) }\end{array}$ \\
\hline 2017 & 13473 & 13473 & 13473 \\
2018 & 13523 & 13523 & 13523 \\
2019 & 13596 & 13594 & 13596 \\
2020 & 13697 & 13696 & 13697 \\
2021 & 13837 & 13836 & 13836 \\
2022 & 14030 & 14028 & 14030 \\
2023 & 14295 & 14291 & 14294 \\
2024 & 14658 & 14651 & 14657 \\
2025 & 15155 & 15142 & 15154 \\
2026 & 15838 & 15814 & 15835 \\
2027 & 16777 & 16737 & 16772 \\
2028 & 18077 & 18005 & 18068 \\
\hline
\end{tabular}

Prediksi harga minyak goreng sawit tanpa kebijakan bea keluar jika dibandingkan dengan harga pada skenario Peraturan Menteri Keuangan No. 136 Tahun 2015 lebih besar dengan rata-rata 0.05 persen pada periode analisis yang dilakukan. Sementara apabila dibandingkan dengan harga pada skenario Peraturan Menteri Keuangan No. 140 Tahun 2016, harga minyak goreng sawit tanpa kebiajakan bea keluar juga lebih besar dengan rata - rata 0.007 persen pada periode yang sama. Meskipun proporsi penurunannya sangat kecil, namun tetap menunjukkan bahwa pajak ekspor tetap berpengaruh pada harga minyak goreng sawit Indonesia (Siregar et al. 2014).

Kedua skenario kebijakan pada sektor industri hilir kelapa sawit yang dilakukan simulasinya terhadap harga minyak goreng sawit tidak menunjukkan 
pengaruh yang besar dibandingkan pengaruh kebijakan tersebut terhadap variabel harga $\mathrm{CPO}$ domestik. Hal tersebut dimungkinkan karena skenario kebijakan yang disimulasikan tidak secara langsung mempengaruhi harga minyak goreng sawit. Skenario kebijakan awalnya akan berpengaruh pada jumlah eskpor CPO yang merupakan bahan baku produksi minyak goreng sawit. Pengaruh pada jumlah ekspor tersebut akan mempengaruhi harga CPO domestik dan kemudian berpengaruh pada biaya produksi minyak goreng sawit sehingga pada akhirnya harga minyak goreng sawit akan meningkat.

\section{Kesimpulan}

Pengembangan biodiesel yang dilakukan Indonesia hingga akhir periode analisis yaitu tahun 2028 belum mampu memenuhi tingkat blending rate yang ditetapkan pemerintah sesuai mandatori biodiesel. Upaya peningkatan ketercapaian tingkat blending rate biodiesel dapat dilakukan dengan pemberian subsidi kepada produsen biodiesel di Indonesia. Kebijakan bea keluar juga dibutuhkan dalam upaya menjaga stabilitas harga CPO domestik dan harga minyak goreng sawit dengan adanya pengembangan biodiesel yang dilakukan Indonesia. Kebijakan bea keluar sesuai Peraturan Menteri Keuangan No. 136 Tahun 2015 lebih efektif menjaga tingkat harga CPO domestik dibandingkan Peraturan Menteri Keuangan No. 140 Tahun 2016. Sedangkan kedua skenario kebijakan bea keluar tidak berpengaruh signifikan terhadap harga minyak goreng sawit Indonesia.

Penelitian selanjutnya terkaitpengembangan industri biodiesel di Indonesia dapat memperluas model sistem dinamik dengan memasukkan produk turunan kelapa sawit lainnya dalam model seperti produk turunan berupa oleokimia dan produk limbah kelapa sawit. Selain itu, skenario kebijakan juga dapat diperluas seperti dengan memasukkan skenario moratorium lahan.

\section{Daftar Pustaka}

Barlas Y. 1996. Formal Aspect of Model Validity and Validation in System Dynamics. System Dynamics Review. 12 (3): 183-210.

[BPS] Badan Pusat Statistik (ID). 2016. Statistik Indonesia 2016. Jakarta (ID): BPS.

[EBTKE] Direktorat Jenderal Energi Baru, Terbarukan dan Konservasi Energi (ID). 2013. Statistik ETBKE 2013. Jakarta (ID): ETBKE, ESDM.

Handoko H, Sa id EG, Syaukat Y. 2012. Permodelan Sistem Dinamik Ketercapaian Kontribusi Biodiesel dalam Bauran Energi Indonesia 2025. Jurnal Manajemen Teknologi. 11(1): 15-27.

Makridakis S, ST Wheelwrigth, VE McGee. 1995. Metode dan Aplikasi Peramalan. Edisi Kedua. Untung SA, A Basith, penerjemah. Jakarta (ID) : Penerbit Erlangga. Terjemahan dari : Forecasting 2nd Edition. 
Mohammadi S, Arshad FM, Bala BK, Iragimov A. 2015. System Dynamics Analysis of the Determinants of the Malaysian Palm Oil Price. American Journal of Applied Sciences. 12 (5): 355-362.

Obado J, Syaukat Y, Siregar H. 2009. The Impacts of Export Tax Policy on the Indonesian Crude Palm Oil Industry. ISSAAS. 15 (2): 107 -119.

Rifin A. 2014. The Effect of Crude Palm Oil Export Tax on Export and Prices. ASEAN Journal of Economics, Management and Accounting. 2 (1\&2): 82-95.

Sembiring MT. 2015. Model Produksi Biodiesel Berbasis Minyak Sawit Untuk Memprediksi Harga Jual dan Besaran Subsidi [Disertasi]. Bogor(ID): Institut Pertanian Bogor.

Sipayung T, Purba J. 2015. Ekonomi Agribisnis Minyak Sawit. Bogor (ID): PASPI.

Siregar MA, Sembiring SA, Ramli. 2014. The Price of Palm-Cooking Oil in Indonesia: Antecedents and Consequences on the International Price and the Export Volume of CPO. Journal of Economics and Sustainable Development. 5(23): 227-234.

Wijaya H. 2015. Perumusan Kebijakan Biodiesel Kelapa Sawit Dengan Menggunakan Metode Regulatory Impact Analysis dan Model Sistem Dinamis [Tesis]. Bogor (ID): Institut Pertanian Bogor. 
JURNAL SOSIAL EKONOMI PERTANIAN

p-ISSN 0853-8395; e-ISSN 2598-5922

Vol. 15, No. 3, Oktober 2019

Lampiran 1 Diagram stock and flow model sistem dinamik dampak pengembangan biodiesel

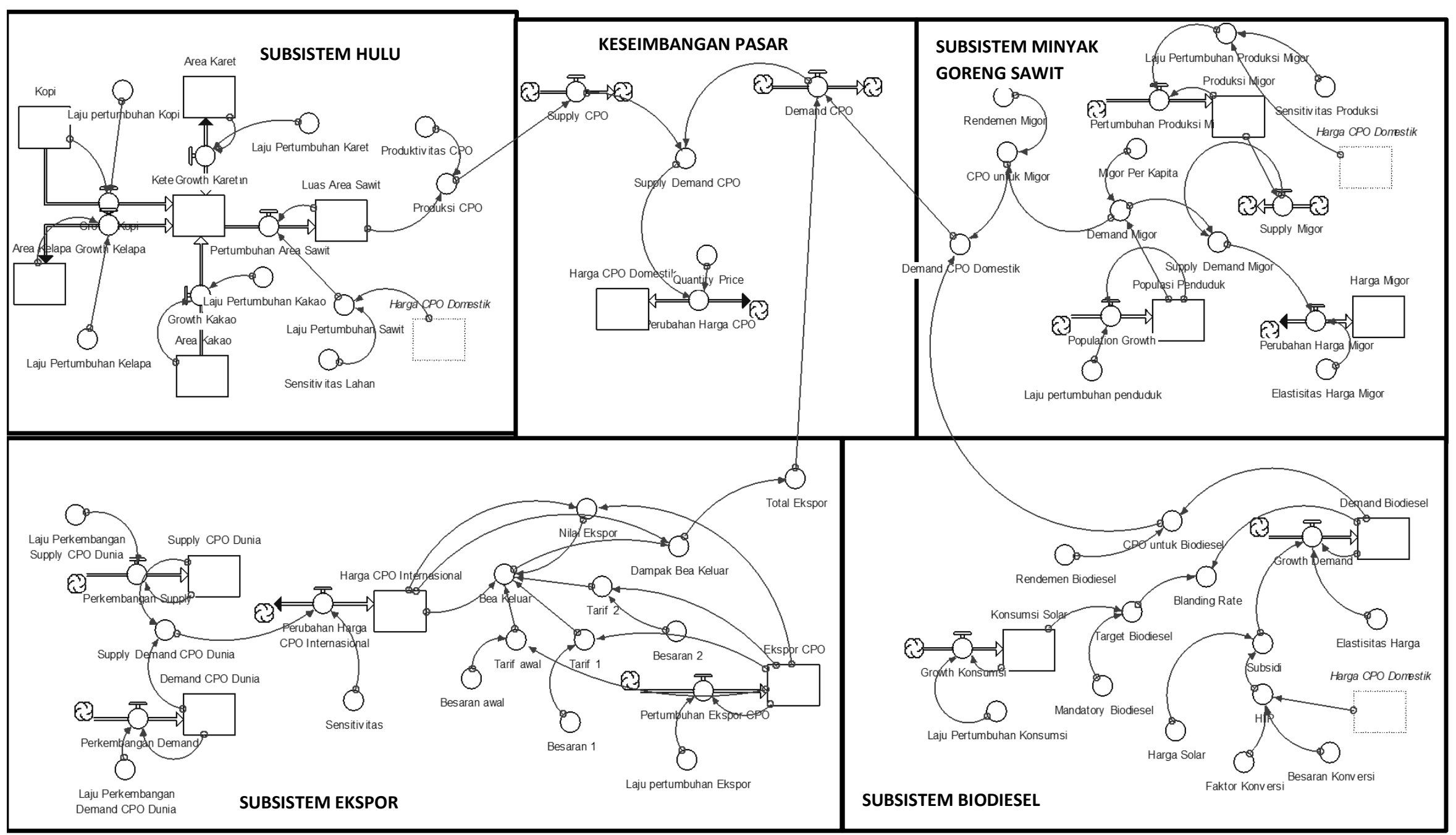

